\title{
Fritz Müller, o naturalista darwinista do Museu Nacional do Rio de Janeiro
}

\section{Fritz Müller, the darwinian naturalist of National Museum of Rio de Janeiro}

\author{
Flavia Pacheco Alves de Souza* \\ Andrea Paula dos Santos Oliveira Kamensky**
}

Resumo: Fritz Müller (1822-1897), naturalista alemão residente no Brasil do século XIX, contribuiu com as ciências biológicas com mais de 264 artigos científicos. Foi naturalista viajante do Museu Nacional do Rio de Janeiro por quinze anos (1876-1891), período em que publicou treze artigos no periódico da Instituição. Este trabalho analisa o período em que Müller foi naturalista do Museu, e em particular, sua amizade com Charles Darwin (1809-1882); visto que, de um simples correspondente e coadjuvante defensor das ideias darwinianas, Müller pode ser compreendido como um pesquisador que, em parceria com Darwin e em diálogo frequente com o estudioso inglês, contribuiu para estabelecer o conjunto das teorias de evolução no século XIX.

Palavras-chave: Fritz Müller. Evolução. Naturalista. Charles Darwin. Museu Nacional

\footnotetext{
*Mestra em Ensino, História e Filosofia das Ciências e Matemática pela Universidade Federal do ABC. Email: flaviapacheco@ufabc.edu.br

**Graduada, Mestra e Doutora em História pela Universidade de São Paulo (USP), Pós-doutora em História da Cieência pela PUC-SP Email: andrea.paula@ufabc.edu.br
} 


\begin{abstract}
Fritz Müller (1822-1897), a german naturalist resident in Brazil who lived in Brazil in the 19th century, contributed to biology in general and is the author of 264 scientific articles. Was traveling naturalist of the National Museum of Rio de Janeiro for fifteen years (1876-1891), during which thirteen articles published in the journal of the Institution. This paper analyzes the period in which Müller was naturalistic Museum, and in particular his friendship with Charles Darwin (1809-1882); given that a corresponding simple and supportive defender of Darwinian ideas, Müller can be understood as a researcher, in partnership with Darwin and frequent dialogue with the english, he helped to establish the set of theories of evolution in the 19th century.
\end{abstract}

Keywords: Fritz Müller. Evolution. Naturalist. Charles Darwin. National Museum

\title{
1. Introdução
}

Morin (2013, p.8) considera a ciência uma atividade complexa, visto que ela é inseparável de seu contexto histórico e social. Para ele, as teorias científicas dão "forma, ordem e organização aos dados verificados em que se baseiam", e por esse motivo são sistemas de ideias, construções do espírito e sujeitas a mudanças no decorrer do tempo (MORIN, 2013, p.22). Dessa forma, o conhecimento científico não é uma evolução linear, de acumulação e de progresso, mas de transformações e rupturas, de continuidades e descontinuidades.

Exemplo dessas transformações e rupturas do conhecimento científico é apontado, principalmente, a partir da revolução cientifica do século XVIII, com os trabalhos de Copérnico e as descobertas de fósseis de espécies já extintos (MAYR, 2009, p.35). Tais pesquisas, em conjunto, trouxeram para reflexão dois fatos importantes: a Terra não era o planeta 'principal' do sistema solar e não havia sido criada recentemente, mas sim há bilhões de anos, contrariando a versão apresentada e aceita na época, descrita no primeiro capítulo da Bíblia, no livro Gênesis.

Neste cenário de questionamentos e descobertas, surge o embrião do que mais tarde se tornaria o evolucionismo, com a publicação de diversos trabalhos, em que a preocupação central era classificar e ordenar as coisas vivas; exemplo da scala naturae ou cadeia geral, que buscava alinhar os seres vivos conhecidos em uma escala do menor ao maior grau de complexidade, tendo no topo, o homem, como representação dos seres humanos (MAYR, 2009, p.40).

Surgem também especulações acerca da mutabilidade das espécies, exemplo do trabalho Zoonomia (1792), do avô de Charles Darwin, Erasmus, que abordou, ainda que de forma tímida, o conceito de transmutação das espécies, sugerindo uma evolução na natureza, conceito amplamente retomado anos mais tarde pelo francês Jean Baptiste de Lamarck (1744-1829). Lamarck 
postulou, em 1809, uma teoria completa sobre evolução que, apesar de tentar explicar os fenômenos da natureza sob tal ótica, continuou caminhando lado a lado com a ideia do criacionismo bíblico (MAYR, 2009, p.27).

Todavia como Mayr (2006, p.13) nos aponta, em todos os escritos dos naturalistas, geólogos e filósofos anteriores a Darwin que tentaram explicar a evolução orgânica, esta sempre era relacionada como obra de Deus, visto que a revolução científica rompeu com a magia e a superstição, porém não retirou do seu discurso a religião, o que acabou trazendo conseqüências adversas à biologia, visto que se Deus governava o mundo por suas leis universais e divinas, estas não poderiam ser caóticas (MAYR, 2009, p.51).

Tal discurso religioso foi posteriormente separado do científico com a publicação, em 1859, do livro On the origin of species by means of natural selection or the preservation of favoured races in the struggle for life (Sobre a origem das espécies por meio da seleção natural ou a preservação de raças favorecidas na luta pela vida), de autoria de Charles Darwin, que buscou fornecer explicações científicas diretas sem o auxílio de um agente sobrenatural, mas criando outra linha de pensamento.

Entendemos que o conjunto das teorias de Darwin propôs um novo alicerce para explicar a vida, negando qualquer visão fisicalista ou vitalista, como as correntes filosóficas opostas vigentes à época apregoavam. Esta nova visão, parte pelos trabalhos desenvolvidos por Darwin, contribuíram para no início do século XX ser proposto o modelo organicista, aceito até a atualidade na biologia.

Morin (2013,p.40-42) considera que toda teoria científica não é objetiva e nem é um reflexo da realidade, mas sim a construção de uma mente (individual ou coletiva) que permite responder a certas perguntas em dado tempo e a uma realidade em particular, desta forma, sendo intrínseca à cultura, à sociedade e à história.

Consideramos o lançamento de Origin e sua posterior aceitação como mudança brusca, a postulação de um novo paradigma científico, que se contrapôs ao dominante, pois este já não conseguia explicar os fenômenos; ou o que Kuhn (2006, p.23-46) denomina de passagem da ciência normal para a ciência extraordinária, momento em que um paradigma cede lugar a um novo, que rompe com as concepções de mundo existentes. Nesse sentido, a ideia linear e cumulativa de ciência, ainda frequente nos livros didáticos atuais de biologia, não se encaixa neste contexto histórico que discutimos de transformações e rupturas, visto que o conjunto das teorias de Darwin não se acumulou ou tentou se ajustar às outras teorias já existentes, como a do criacionismo, mas sim se tornou incomensurável a esta visão (KUHN, 2006, p.47-55). Isto porque a crença individual de cada espécie criada por um ser superior foi refutada pela teoria da origem comum, de que todas as formas de vida descendem de um ancestral. Darwin ainda ousou em propor que esta evolução a partir de um 
ancestral comum não leva ao progresso e nunca à perfeição, contrariando a scala naturae de ordenação da natureza em que o ser humano aparece no topo como o ser perfeito.

Mayr (2009, p.29) também considera a publicação de Origin um paradigma que propôs uma revolução intelectual, visto que Darwin não só apresentou um discurso científico com evidências de que a evolução ocorria, mas explicou o porquê, a partir da construção de um determinado olhar sobre os fenômenos da natureza e acerca dos seres vivos, estes não estariam subjugados a poderes ou forças sobrenaturais, através da observação de fenômenos que, para este autor, "qualquer um podia observar todos os dias na natureza" (MAYR, 2009, p.29). Além disso, dentre o conjunto das teorias de Darwin, o conceito da seleção natural é único, não se encontrando nada semelhante em qualquer outro escrito filosófico anterior ou contemporâneo a ele. Para Darwin, não é o ambiente que seleciona, mas o organismo que enfrenta o ambiente com muito ou pouco sucesso.

Ao conjunto das teorias de Darwin foi proposto o termo darwinismo, cunhado em 1864 por Thomas Huxley (1825-1895), para se referir às ideias evolutivas que tinham influência de Darwin. Porém, conforme nos alerta Mayr (2008, p.90) desde então, nunca houve consenso por parte da comunidade científica, visto que cada autor trata apenas de aspectos do darwinismo que lhe convém e não do conjunto das premissas propostas por Darwin. Este fato revela a complexidade e a heterogeneidade dos discursos e dos conhecimentos científicos em circulação, muitas vezes vulgarizados e simplificados de forma linear, e ainda com a construção histórica já fartamente criticada de grandes heróis cientistas para apresentar e justificar a ciência como discurso dono da verdade e os produtos do conhecimento científico como fenômenos naturalizados e inevitáveis da história da humanidade.

Exemplo dessa complexidade e heterogeneidade dos discursos e dos conhecimentos científicos em torno do conjunto de teorias da evolução é demonstrado já entre os primeiros defensores do darwinismo: o próprio Huxley, que cunhou o termo, não aderiu ao conceito de seleção natural; Alfred Russel Wallace, co-autor da teoria, não admitia que os seres humanos deveriam ser colocados na mesma escala com os animais; Ernst Haeckel, que introduziu as ideias de Darwin na Alemanha, tornou-se no final de 1890 um neolamarckista; sobrando apenas Fritz Müller, considerado pela historiografia o autor que mais se aproximou do conjunto das teorias de Darwin (LOPES, 2009, p.23; WEST, 2009, p.45), responsável por inúmeras pesquisas que forjaram sua validação, justificando, aprimorando e criando conceitos em torno da mesma por meio de seu olhar e de sua escrita sobre a natureza que observou no Brasil do século XIX.

O evolucionismo, principalmente o darwinismo, teve grande influência nas publicações do Museu Nacional do Rio de Janeiro. Analisando os trabalhos dos primeiros volumes dos Archivos do Museu Nacional ${ }^{1}$, periódico de 
divulgação científica da Instituição, percebemos grande influência das ideias de evolução, principalmente das teorias de Darwin, constituindo-se, um coletivo de pensamento; ainda que seus autores não chegassem a um consenso acerca do tema e que muitas vezes só utilizassem o nome de Darwin como forma de oferecer credibilidade científica.

Gualtieri (2009), que realizou análise dos Archivos buscando demonstrar a influência das teorias gerais da evolução nas publicações, aponta que, a partir de 1870, três tipos de evolucionismo ganharam expressão em diferentes segmentos no Brasil: o evolucionismo darwinista, o spenceriano e o haeckeliano. O então diretor do Museu, Ladislau Netto (1838-1894), apesar de utilizar termos vinculados às teorias de Darwin, como "luta pela vida", em seus trabalhos, também era favorável às ideias de Lamarck, acerca dos hábitos condicionados que levam à adaptação e, por conseguinte, ao evolucionismo haeckeliano, que também se utilizava destas ideias para explicar o processo de variação proposto pela seleção natural de Darwin. Para a autora, dentre todos os naturalistas do período, apenas Fritz Müller foi o que mais dialogou com Darwin e com o conjunto de suas proposições. (GUALTIERI, 2009, p.51-52).

Também é importante ressaltar que o darwinismo iniciou sua disseminação fora das instituições científicas e de pesquisa no Brasil em 1875, através de conferências do Dr. Augusto Cesar Miranda de Azevedo nas Conferências Populares da Glória, realizadas na cidade do Rio de Janeiro. Estas Conferências repercutiam na imprensa cariosa e se constituíram como um espaço formador de opinião pública (CARULA, 2007, p.46-62), realizando desta forma uma repercussão popular dessa nova forma de conceber a ciência natural, apoiada por este coletivo de pensamento favorável a Darwin, sustentado pelo novo paradigma.

\section{O naturalista Fritz Müller}

Um cientista que optava por viajar pelo mundo realizando descrições textuais e desenhos acerca da fauna e flora dos locais por onde passasse, era considerado um naturalista viajante no século XIX, diferenciando-se daqueles cientistas de gabinete, como eram chamados os pesquisadores concentrados nos Museus e nas Universidades que não saíam a campo, só analisavam materiais enviados de diversas partes do mundo. Ambos os modos de se fazer ciência coexistiam no século XIX (KURY, 2001, p.864).

No Museu Nacional, o cargo de naturalista viajante era indicado àqueles com formação e conhecimento das ciências naturais, que fosse habilitado para preparar coleções (zoológicas, botânicas, antropológicas, arqueológicas, etc.) provenientes de diversas Províncias do Brasil, para posteriormente enviá-las ao Museu, acompanhadas de estudos e classificações a serem publicados no periódico Archivos. Após a formalização do cargo em 1876, o número de naturalistas viajantes era fixado pelo Ministério da Agricultura, Comércio e 
Obras Públicas sobre a proposta do Diretor Geral do Museu Nacional (BRASIL, 09 fev. 1876). Em 1892, com a obrigatoriedade dos naturalistas residirem no Rio de Janeiro, o cargo mudou para 'naturalista ajudante', cujas funções eram ajudar os diretores de Seção na classificação e outros trabalhos técnicos in locu, bem como realizar excursões para aquisição de produtos e artefatos indígenas, principalmente (KEULLER, 2012, p.99).

Johann Friederich Theodor Müller, ou simplesmente Fritz Müller, nasceu no dia 31 de março de 1822, na aldeia de Windischholzhausen, distrito de Erfurt, na Thüringen (Turíngia), Prússia, no que hoje seria a região central da atual Alemanha. Formado em filosofia, emigrou ao Brasil acompanhado de sua esposa Karoline e sua filha Johanna em 1852, vivendo na então colônia de Blumenau-SC até sua morte em 1897.

Müller escreveu 264 trabalhos científicos (SCHLENZ; FONTES; HAGEN, 2009, p.48-61), a maioria sobre temas relacionados à evolução, fauna, flora e ecologia brasileiras. Escreveu apenas um livro, publicado em 1864 na Alemanha, Für Darwin (Para Darwin), em que dialogou com as teorias evolutivas propostas e sistematizadas cinco anos antes por Darwin para aplicálas em seus estudos sobre os crustáceos do Brasil (MÜLLER, 2009, p.5). A relevância do livro foi tanta que o próprio Darwin, quando teve contato com o livro e sua originalidade, ocupou-se em providenciar a tradução do original em alemão para o inglês, comunicando a Müller periodicamente o progresso da tradução e as vendas dessa edição, conforme correspondências entre os dois naturalistas traduzidas por Zillig (1997, p.167;169;175;178;183;184;187).

Müller foi contratado pelo Museu Nacional no dia 16 de setembro de 1876 (LIVRO $A \ldots, 16$ set. 1876). No ofício de contratação, assinado pelo conselheiro José Fernandes da Costa Pereira Junior, então Ministro e Secretário de Estado dos Negócios da Agricultura, Comércio e Obras Públicas e pelo Dr. Ladislau Netto, diretor interino do Museu Nacional, é recomendado ao imperador D. Pedro II, autorização para contratação do Dr. Fritz Müller em caráter oficial no cargo de naturalista viajante, devido aos préstimos que este já realizara a ciência mundial e em grande parte publicada em colaboração com Charles Darwin, demonstrando novamente, pela simples menção do nome 'Darwin', o novo coletivo de pensamento do Museu Nacional pautado nos ideais evolucionistas. Além de recomendá-lo cientificamente, o ofício ainda expõe que Müller vivia na província de Santa Catarina "velho, pobre, sobrecarregado de numerosa família", afirmando que a contratação também o ajudaria em suas provisões.

Percebe-se certo exagero no ofício em relação à situação financeira de Müller. Apesar de na época viver acompanhado da esposa e sete filhas (Anna, Rosa, Agnes, Emma, Thusnelda, Selma e Linda), Müller possuía plantações e criações de animais para o consumo doméstico, e recebia uma quantia em dinheiro de pensão do período em que fora professor em Desterro. Mais tarde, 
quando o irmão Wilhelm chega à sua casa em 1883, este escreve para a mãe na Alemanha dizendo que o salário do irmão fazia com que sua família vivesse confortavelmente, tanto para os padrões locais como para os alemães (ZILLIG, 2004, p.58). Além disso, é bom recordar que Müller não era homem dado aos luxos: vivia sempre descalço, com calça e camisa, conforme relato de seu irmão em carta à mãe datada de 28 de agosto de 1883: "Fritz anda em geral muito simples e também sua mulher e filhos; Fritz se preocupa pouco ou nada com a aparência, prefere andar descalço, com calça e camisa" (ZILLIG, 2004, p.58).

Em sua contratação, o Museu o gratificaria com duzentos mil réis (200\$000) mensais para não somente se encarregar de fazer coleções zoológicas e botânicas, mas também arqueológicas e antropológicas, com referência ao estudo dos sambaquis, ao longo da costa meridional do Brasil.

Os sambaquis são enormes montanhas de conchas de moluscos e ossos encontrados em baías, praias ou na foz de rios, erguidos por povos que habitaram o litoral do Brasil em períodos pré-históricos. As explicações possíveis quanto à finalidade destas construções é que, além de servirem como depósitos de restos de alimentos, serviriam também como sepulturas de humanos. O diretor do Museu, Dr. Ladislau Netto, possuía grande interesse pelos estudos antropológicos e arqueológicos e, dessa forma, o estudo destas estruturas, "recém descobertas" por naturalistas em comissões, era essencial para o "progresso da ciência" no período. Os sambaquis existentes no litoral de Santa Catarina foram estudados pelo Museu em diversas comissões, lideradas por Carlos Wiener, Carlos Schreiner (1849-1896) e Hermann Ihering (18501930).

Apesar de Müller não ter publicado nos Archivos nenhuma pesquisa acerca dos sambaquis existentes no litoral de Santa Catarina, sabemos que ele acompanhou a expedição liderada por Carlos Wiener, que culminou em publicação no primeiro volume dos Archivos (WIENER, 1876, p.1-20). Apesar de Wiener não fazer referência a Müller na excursão científica, sabemos desse fato por correspondência de Müller endereçado a Darwin, de 25 de dezembro de 1875, no qual comenta com o amigo sobre esta excursão, bem como fornece a ele informações específicas sobre os sambaquis, conforme o trecho disponível a seguir:

Em Desterro me encontrei com dois jovens senhores (M. Charles Wiener, de Paris e M. Carl Schreiner, do Museu Nacional do Rio) os quais, por ordem do governo brasileiro, estiveram examinando os 'sambaquis' de nossa província. Eu os acompanhei em algumas de suas excursões. Estes 'sambaquis' ou 'casqueiros' são pequenas colinas de conchas acumuladas pelos antigos habitantes de nossas costas; eles existem em grande número, e alguns deles agora se encontram à distância de diversas milhas do litoral, 
embora originalmente eles eram, naturalmente, formados próximos aos locais onde as conchas vivem. Alguns são de tamanho considerável; nos foi dito que um sambaqui em uma pequena ilha próximo a São Francisco tinha a altura de cerca de 100 metros; mas o maior que eu mesmo vi, não excedia a 10 ou 12 metros. Os sambaquis podem ser classificado em três classes segundo as conchas de que são formados [...]. Entre as ferramentas que são encontradas nos sambaquis, os machados de pedra, são, de longe, os mais frequentes. Mas, como o M. Wiener provavelmente publicará em breve um completo relato de suas pesquisas, não quero repisar este assunto (ZILLIG, 1997, p.198).

Müller publicou nos Archivos treze trabalhos, somando 185 páginas, distribuídas em quatro volumes do periódico, conforme tabela 1 a seguir:

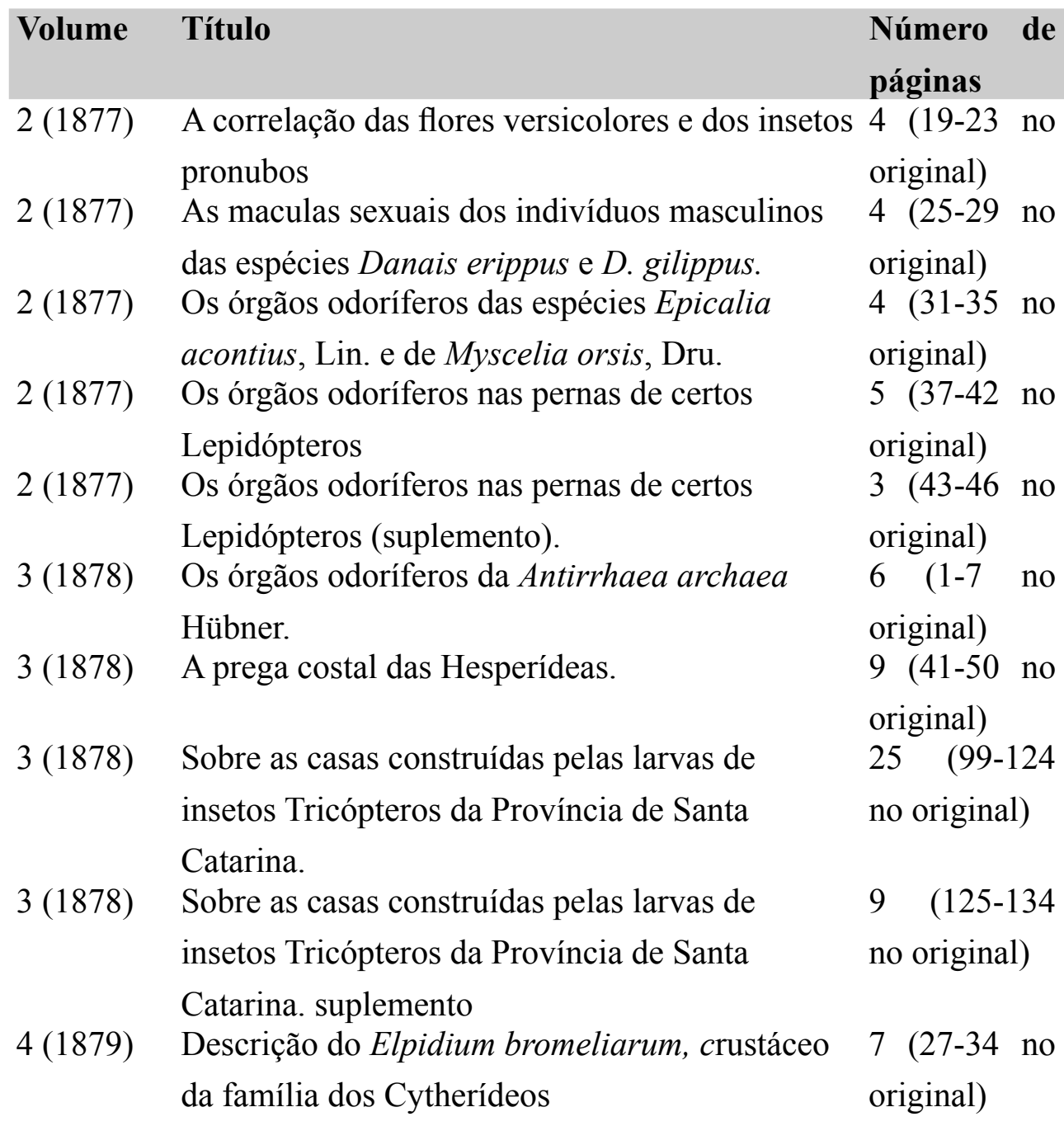


4 (1879) A metamorfose de um inseto díptero (quatro

38 (47-85 no partes)

original)

8 (1892) Trichodactylus, siri de água doce, sem

$8 \quad(125-133$ metamorfose

no original)

8 (1892) O camarão miúdo do Itajaí, Atyoida Potimirim

$23 \quad(155-178$

no original)

8 (1892) O camarão preto, Palaemon Potiuna

$27 \quad(179-206$

no original)

8 (1892) Descrição da Janira exul, crustáceo isópode do 13 (207-220

Estado de Santa Catarina no original)

Tabela 1: Artigos publicados por Müller no período Archivos do Museu Nacional

Analisando a tabela, percebemos que os trabalhos de Müller foram publicados no periódico anualmente até o volume IV, de 1879. Após esse período há uma lacuna de treze anos até suas próximas publicações, que ocorreram no volume VIII de 1892, período em que já não mais integrava o quadro de funcionários da instituição. Tal situação pode ser explicada pela falta de verbas para impressão da revista e também pela morte de sua filha Rosa, o que causou a Müller um grande abalo emocional.

Em relação à falta de verbas para a impressão, conforme o Regulamento de 1876 (BRASIL, 09 fev. 1876), a revista Archivos do Museu Nacional deveria ser publicada trimestralmente, objetivo que nunca foi alcançado por falta de verbas e atraso nas impressões, conseguindo uma periodicidade anual até o volume IV. O volume V aparece dois anos depois, em 1881, e nele há apenas um trabalho: a publicação na íntegra de Florae fluminensis seu, descriptionum plantarum praefectura fluminensi sponte nascentium liber primus ad systema, de autoria de José Mariano da Conceição Vellozo (1742-1811), obra concluída em 1790, mas que só foi parcialmente publicada em 1825. Já o volume VI, aparece quatro anos depois, em 1885, com apenas quatro artigos sobre arqueologia e antropologia; e o volume VII em 1887, com apenas um trabalho sobre paleontologia.

Além disso, a partir do volume VI do periódico (1885), notamos uma mudança na linha de pesquisa das publicações, que passam a se dedicar exclusivamente aos estudos antropológicos e arqueológicos. Parte dessa mudança de temática deve-se à própria mudança de interesses do diretor do Museu, Dr. Ladislau Netto, em consonância com a visão mundial de antropologia da época, que buscava recolher aos museus, para abrigo em coleções, a cultura das populações que estavam sendo dizimadas (LOPES, 2009, p.170). 
Também atribuímos esta ausência de trabalhos de Müller no periódico durante estes treze anos também à morte de sua filha predileta, Rosa, que se suicidou, em Berlim, no dia 12 de junho de 1879. A morte de Rosa foi um choque para Müller, que via nesta filha uma possível continuadora de seu trabalho. Pelos seus desabafos em cartas a amigos, é nítido ver sua tristeza latente, como escreve, por exemplo, para Darwin em julho deste ano:

Com a morte de Rosa, toda a alegria e vontade de viver desapareceram. Eu coleto, observo, desenho, descrevo sem motivação e vontade, somente para entregar minha colaboração regular para os nossos Archivos do Museu (ZILLIG, 1997, p.49).

Devido a esta falta de rendimentos ao Museu Nacional nestes anos dolorosos, em 04 de fevereiro de 1884, o Dr. Ladislau Netto envia ofício ao imperador D. Pedro II, pedindo permissão para dispensar os serviços de Müller, conforme transcrito a seguir:

Ilustríssimo e excelentíssimo senhor cumprindo-me realizar
a maior economia nas despesas normais deste Museu,
consoante as ordem que de Vossa Excelência tenha tido a
honra de receber e parecendo-me dispensáveis atualmente
o serviço de um dos três naturalistas viajantes especialistas
na Zoologia, não só por ser demasiado este número numa
só especialidade; como porque um deles, o Dr. Frederico
Müller fixou-se completamente em Blumenau onde, pela
vida sedentária que ali passa, pouco ou nenhum serviço
tem prestado nestes últimos anos ao Museu Nacional, não
podendo ou não querendo afastar-se daquele centro de
população, donde não me pode ser de nenhuma utilidade,
rogo a vossa excelência se digne autorizar-me a dispensar o
referido Naturalista viajante e a conservar vago o lugar até
que pela Presidência do Amazona me cheguem informações
precisas sobre as habilitações do Conde Stradelli, que ali se
acha a alguns anos em trabalhos etnográficos, e a quem o
Museu Nacional deve valiosos presentes nesta especialidade
(LIVRO B..., 04 fev. 1884).

Müller teve conhecimento de sua suspensão do cargo em 29 de fevereiro de 1884, conforme nos relata uma testemunha ocular da época, seu irmão Wilhelm. Quanto à suspensão, este conta em carta à mãe, que:

O próprio Fritz suporta isto com muita serenidade, pois há possibilidades de vir a recuperar seu cargo. Em seu modo de ver, o dinheiro tem um valor muito pequeno. Para sua 
esposa é mais difícil de suportar (ZILLIG, 2004, p.64).

Além da falta de rendimentos de Müller ao Museu Nacional devido à morte de Rosa, bem como a mudança de rumo das linhas de pesquisa da instituição, soma-se a esta possível destituição do cargo, o envolvimento de Müller na política de Blumenau, que à época já havia sido elevada a município (ocorrido em 1880), e que contava com uma população de cerca de vinte mil habitantes.

Após a enchente que assolara o município em 1882, o governo provincial enviara uma Comissão ao local para reparar os danos causados, contratando muitos colonos para trabalhar nas obras, os quais não foram pagos pelos serviços. Esta falta de pagamentos gerou duas correntes opostas: uma que defendia o governo e outra que defendia os colonos trabalhadores. Müller ficou ao lado dos trabalhadores, publicando opiniões inflamadas contra o governo na gazeta local Blumenau Zeitung; o que acabou criando para ele um ambiente de tensão e conflito, visto que seu cargo que era mantido pelo governo imperial. (CASTRO, 1997, p.125-126).

Sua demissão, porém, não durou muito ${ }^{2}$, parte pela pressão pública e política, que fez com que seu cargo fosse restabelecido oito dias após a suspensão, conforme nos relata seu irmão, em trechos de duas cartas à mãe na Alemanha:

Desejo escrever-lhe bem sucinto para comunicar que Fritz já recebeu novamente seu cargo; antes que a notícia da suspensão do cargo chegasse aqui, ela já havia sido reconsiderada e com o correio de hoje chegou a correspondente notícia. Os senhores no Rio devem ter reconhecido que, aos olhos da ciência mundial, eles e o Brasil não poderiam se desmoralizar de forma mais desgastante do que através de uma medida destas. (...) Por ocasião de sua recontratação, fez-se a exigência ao Fritz para que, no interesse do Museu, ele faça viagens mais frequentes. Para mim está bom, assim eu terei algumas coisas para ver. (...).

A coisa se situa de tal forma que Netto (o diretor) precisou, contrariado, ceder às pressões de cima, em partes políticas em parte de inimigos pessoais que tem em Fritz como causa; que deve se agradecer aos seus esforços à rápida readmissão. Que em todo caso se daria de outra forma, rápido o suficiente, pressionado pela opinião pública. Com o regulamento, supostamente ele quis proporcionar ao autor da história e para não ficar demasiado mal junto ao Fritz, ele em articular imediatamente o elevou em $3 / 4$. A história me parece tão característica para as condições brasileiras, que 
julguei valer o trabalho de relatá-la (ZILLIG, 2004, p.64).

Após o declínio do governo imperial e estabelecimento do regime republicano pós 1889 , o Museu Nacional, subordinado ao recém-criado Ministério da Instrução Pública, Correios e Telégrafos, passou por diversas reorganizações, sendo que a principal, que atingiu diretamente o cargo de Müller, foi a de 1891, que regulamentava que todos os naturalistas viajantes do Museu deveriam ser residentes da cidade do Rio de Janeiro, e que deveriam assinar ponto diário no estabelecimento.

Müller, que nunca chegou a conhecer o Rio de Janeiro, pediu sua exoneração do cargo no dia 18 de julho de 1891 (LIVRO C..., 18 jul. 1891), em virtude de não querer mudar sua residência de Santa Catarina.

Hermann Ihering (1850-1930), em carta datada de 28 de janeiro de 1892 a Orville Derby (1851-1915), que também integrara o quadro do Museu, comenta que parte das novas decisões instituídas pelo Regulamento eram estritamente políticas para destituir Müller de seu cargo, visto que ele, "é considerado um líder entre os alemães e todos os políticos locais que não conseguem seu apoio estão propensos a trabalhar contra ele." (LOPES, 2009, p.195).

O fato é que a saída de Müller do Museu causou repercussão nos jornais brasileiros e na mídia internacional, exemplo do artigo de Emílio Goeldi (1859-1917) submetido à revista Nature, no qual criticava a ignorância do governo brasileiro face à atitude com Müller, que certamente não ocorreria se fosse aos tempos do Imperador (LOPES, 2009, p.197). O diretor Netto rebate tal crítica defendendo o governo republicano e afirmando que Müller só ficou tantos anos entre os funcionários por seu empenho, visto que há muito, seus compromissos com o Museu já haviam sido questionados,

O homem vítima da estulta burocracia do Brasil, o sábio maltratado pela administração brutal deste país foi por mais de dezesseis anos empregado do Museu, mas nunca aí pôs sequer os pés, porque nunca viu esta Capital, nunca veio ao Rio de Janeiro (NETTO, 31 jan. 1892).

Roquette-Pinto em seu discurso, Glória sem rumor de 1920, também comenta sobre a saída de Müller do Museu Nacional. Para ele,

Não há fábula que se tenha inventado a propósito desse lamentável acontecimento. De uns ouvi que Fritz Müller foi demitido a 'bem do serviço público'; de outros, que, uma vez demitido, sofreu grandes privações e passou a andar descalço, qual mísero mendigo... E tantas coisas mais. A verdade é que as atitudes religiosas e até mesmo 
administrativas, clamando com desassombro (mit scharfen Worten) contra o que the parecia irregular; a sua intransigente obsessão do Deutschtum, que não podia ser perdoada; a sua inquebrantável independência moral; o seu gosto pela ampla liberdade, e mesmo os seus princípios filosóficos - que o levaram a abençoar o cabo do machado - tudo isso, explica o incidente (ROQUETTE-PINTO, 2000, p.31).

Independente de quais foram os motivos reais que afastaram Müller de seu cargo, algumas coisas são certas: ele próprio pediu sua demissão face ao novo Regulamento e a destituição não o deixou pobre, a ponto de ter que andar descalço pelas ruas conforme boatos da época e veiculados por RoquettePinto em seu discurso. Sobre esse assunto, a bisneta de Müller, Tula Mayer, em entrevista concedida ao documentário Fritz (2009), comenta que seu pai, quando viu a estátua erguida em Blumenau, em homenagem a Fritz Müller, exclamou: "Este não é o meu avô! Ele nunca andou calçado!"

Gustav Stutzer, pastor alemão residente em Blumenau em 1886, também descreve Müller em seu livro de Memórias, publicado na Alemanha em 1928. A figura de Müller era tão exótica e singular que foi descrita da seguinte forma:

Logo depois da nossa chegada, notei um senhor que toda manhã, às nove horas, a passos lentos e largos, cruzava o centro da cidade. Não olhava nem para a direita e nem para a esquerda, e não respondia aos cumprimentos dos passantes. Sua aparência era tão estranha quanto ao seu comportamento. Descalço, ou de sandálias, magro e alto, vestia calças brancas de sarja, amarradas na cintura com um cinto preto, onde trazia pendurado um facão. Uma comprida bengala acompanhava seus passos lentos. Toda a figura dava a impressão de um autômato. No entanto, a lata coletora verde que levava nas coisas fazia saber que se tratava de um colecionador. Era sem dúvida uma figura muito original (CASTRO, 1997, p.126).

\section{As influências de Müller}

Apesar de Müller viver à época fora do círculo científico do país (cidade do Rio de Janeiro) e também distante dos círculos europeus nos quais era constantemente citado, em todas as discussões de seus trabalhos, notamos que ele tinha conhecimento de vasta literatura acerca dos assuntos específicos que tratava. Exemplo disso são as citações encontradas em seus trabalhos a outros autores, bem como a transcrição de excertos de obras que viessem a corroborar com seu pensamento e pesquisa. Parte dessa literatura chegava a Müller através de seu irmão, Hermann, que vivia na Alemanha, ou remetida por amigos, exemplo de Darwin que enviava a ele periodicamente, cópias de 
seus livros, bem como de outros autores, recentemente publicados na Inglaterra.

Em seus trabalhos dos Archivos, há referências a diversos pesquisadores contemporâneos ou anteriores a ele. Em seu primeiro trabalho (MÜLLER, $1877 a$, p.19-23), por exemplo, há referências ao botânico italiano Giacomo Giuseppe Federico Delpino (1833-1905). Müller se utiliza dos trabalhos de Delpino realizados na Universidade de Gênova como referencial para tratar da relação de insetos polinizadores com plantas específicas. Ele mesmo cita o livro do autor Ulteriori osservazioni e considerazioni sulla dicogamia nel regno vegetale (1868 e 1870); que trata, dentre outros assuntos pertinentes ao reino vegetal, das investigações do autor acerca da mudança da cor das flores, as quais determinavam o momento certo para que os insetos polinizadores retirassem o néctar e pólen (DELPINO, 1996, p.326). Neste mesmo artigo, Müller faz referência ao botânico português Felix Avellar Brotero (1744-1828) e à sua obra Compêndio de Botânica (1788), publicada em dois volumes. Para justificar a ausência de estudos acerca da significação biológica da mudança de coloração em flores, vale-se de excerto retirado do Tomo II do Compêndio, demonstrando seu conhecimento como leitor acerca do assunto que dissertava.

Nos artigos que tratam sobre os órgãos odoríferos presentes em machos de certas espécies de lepidópteros (MÜLLER, 1877b, p.25-29), Müller utiliza referências de entomólogos como Edward Doubleday (1811-1849) e John Obadiah Westwood (1805-1893), cuja obra publicada em dois volumes Genera of diurnal lepidoptera (1846-1852), era muito utilizada na época. Também se utiliza do Catalogue of Diurnal lepidoptera of the family Satirydae in the collection of the British Museum, de autoria de Arthur Gardiner Butler (18441925), publicado em 1868 em Londres, comparando seus resultados com os encontrados por este autor para espécimes de borboletas européias (MÜLLER, 1878, p.1-8).

Outro autor também citado por Müller em diversos artigos (MÜLLER, 1879, p.27-34; MÜLLER, 1892, p.125-133) é Hermann August Hagen (18171893), que publicou em 1862 (vol. 1) e 1863 (vol. 2) o livro Bibliotheca entomologica, Die Litteratur über das ganze bebiet der entomologie, bis zum jahre, utilizado como referência aos estudos entomológicos da época.

Acreditamos que Müller se utilizava de tantas referências em seus trabalhos para fornecer credibilidade às suas pesquisas, como forma de demonstrar que, mesmo longe do mundo científico, suas pesquisas estavam em consonância com as atuais publicações da Europa, mesmo sendo desenvolvidas na tão longínqua Província de Santa Catarina. Além disso, notamos que Müller, como um bom naturalista de seu tempo, era detalhista e descritivo, mas se distanciava destes por também ser um grande teórico, aproximando-se neste caso, de um cientista moderno.

No quadro 1, disponibilizamos as 28 referências citadas por Müller em seus trabalhos desenvolvidos no Museu Nacional. Pela familiaridade com que 
o autor as cita, indicando até mesmo os números de páginas das respectivas obras, acreditamos que estes livros faziam parte da biblioteca particular de Müller, cabendo realizar uma pesquisa aprofundada no Arquivo Histórico de Blumenau-SC para investigar se estes livros ainda se encontram preservados na cidade.

\begin{tabular}{|c|c|c|}
\hline Autor & Obra consultada & Ano \\
\hline $\begin{array}{l}\text { Arthur Gardiner } \\
\text { Butler (1844-1925) }\end{array}$ & $\begin{array}{l}\text { Catalogue of diurnal lepidoptera of the } \\
\text { family Satyrid in the collection of the } \\
\text { British Museum }\end{array}$ & 1868 \\
\hline $\begin{array}{l}\text { Augustin François de } \\
\text { Saint-Hilaire (1779- } \\
1853)\end{array}$ & Voyage au Brésil, (Tomo III) & 1830 \\
\hline $\begin{array}{l}\text { Camil Heller (1823- } \\
\text { 1917) }\end{array}$ & Die crustaceen des sudlichen Europa & 1863 \\
\hline $\begin{array}{l}\text { Carl Gegenbaur } \\
(1826-1903)\end{array}$ & Grundzüge der vergleichenden anatomie & 1870 \\
\hline $\begin{array}{l}\text { Carl Siebold (1808- } \\
1883)\end{array}$ & $\begin{array}{l}\text { Lehrbuch der vergleichenden anatomie } \\
\text { der Wirbellosen Thier }\end{array}$ & 1848 \\
\hline $\begin{array}{l}\text { Charles } \quad \text { Robert } \\
\text { Darwin (1809-1882) }\end{array}$ & $\begin{array}{l}\text { The descent of man and selection in } \\
\text { relation to sex. }\end{array}$ & 1871 \\
\hline $\begin{array}{l}\text { Charles } \quad \text { Robert } \\
\text { Darwin (1809-1882) }\end{array}$ & Origin of species ( $4^{\mathrm{a}}$ ed.) & 1866 \\
\hline $\begin{array}{l}\text { Charles Robert } \\
\text { Darwin }(1809-1882)\end{array}$ & A monograph on the fossil lepadide & 1851 \\
\hline 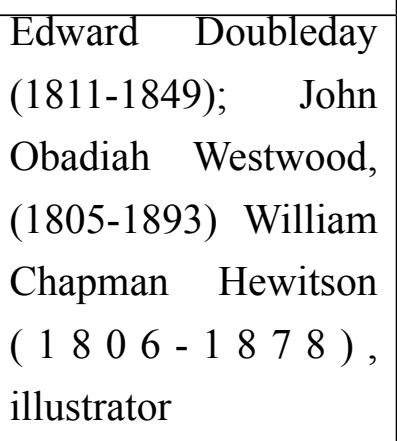 & Genera of diurnal lepidoptera & $\begin{array}{l}1850- \\
1852\end{array}$ \\
\hline $\begin{array}{l}\text { Félix Avelar Brotero } \\
(1744-1828)\end{array}$ & Compendio de botânica (Tomo I) & 1788 \\
\hline
\end{tabular}




\begin{tabular}{|c|c|c|}
\hline $\begin{array}{l}\text { Franz von Leydig } \\
(1821-1908)\end{array}$ & $\begin{array}{l}\text { Lehrbuch der histologie des menschen } \\
\text { und der thiere }\end{array}$ & 1857 \\
\hline $\begin{array}{ll}\text { Frederico } & \text { Delpino } \\
(1833-1905) & \end{array}$ & $\begin{array}{l}\text { Ulteriori observazioni sulla dicogamia } \\
\text { nel regno vegetale. (Part. II, fasc. } 25 \text { ) }\end{array}$ & 1868 \\
\hline $\begin{array}{lr}\text { Gottlieb } & \text { August } \\
\text { Wilhelm } & \text { Herrich- } \\
\text { Schäffer } & (1799-1874)\end{array}$ & Prodom. System. Lepidopt. (Fasc. III) & 1868 \\
\hline $\begin{array}{l}\text { Schatfer }(1 / 99-18 / 4) \\
\text { Hermann Hagen } \\
(1817-1893)\end{array}$ & $\begin{array}{l}\text { Ueber phrygariden gehauese stettiner } \\
\text { entomol. Zeitung XXV }\end{array}$ & 1864 \\
\hline $\begin{array}{l}\text { Henri Milne-Edwards } \\
(1800-1885)\end{array}$ & $\begin{array}{l}\text { Histoire naturelle des crustacés (Tomo } \\
\text { V) }\end{array}$ & 1834 \\
\hline $\begin{array}{l}\text { Henri Milne-Edwards } \\
(1800-1885)\end{array}$ & $\begin{array}{l}\text { Lecons sur la physiologie Et L'anatomie } \\
\text { comparee de L'homme et des animaux } \\
\text { (Tomo V) }\end{array}$ & 1857 \\
\hline $\begin{array}{l}\text { Henrik Nikolai } \\
\text { Kröyer (1799-1870) }\end{array}$ & $\begin{array}{l}\text { Monografisk fremstilling af slaegten } \\
\text { Hippolyte's nordiske arter }\end{array}$ & 1838 \\
\hline $\begin{array}{ll}\text { Hermann } & \text { Müller } \\
(1829-1882) & \end{array}$ & Befruchtung der Blumen durch insekten & 1873 \\
\hline $\begin{array}{l}\text { Jean-Charles Chenu } \\
(1808-1879)\end{array}$ & $\begin{array}{l}\text { Encyclopédie d'histoire naturelle, } \\
\text { papillons, (Tomo II) }\end{array}$ & $\begin{array}{l}1850- \\
1861\end{array}$ \\
\hline $\begin{array}{l}\text { Johan Axel Palmen } \\
(1845-1919)\end{array}$ & Zur morphologie des tracheensystems & 1877 \\
\hline $\begin{array}{l}\text { John } \\
\text { Westwood } \\
1893)\end{array}$ & $\begin{array}{l}\text { An introduction to the modern } \\
\text { classification of insects : founded on } \\
\text { the natural habits and corresponding } \\
\text { organisation of the different families } \\
\text { (Tomo II) }\end{array}$ & 1839 \\
\hline $\begin{array}{l}\text { Oscar Harger (1843- } \\
1887)\end{array}$ & $\begin{array}{l}\text { Report on the marine Isopoda of New } \\
\text { England and adjacent waters. }\end{array}$ & 1880 \\
\hline $\begin{array}{l}\text { Pierre Joseph Van } \\
\text { Beneden }(1809-1894)\end{array}$ & $\begin{array}{l}\text { Recherches sur la faune littorale de } \\
\text { Belgique }\end{array}$ & 1831 \\
\hline $\begin{array}{l}\text { Thomas Henry } \\
\text { Huxley (1825-1895) }\end{array}$ & $\begin{array}{l}\text { Amanual of the anatomy of invertebrated } \\
\text { animals }\end{array}$ & 1877 \\
\hline
\end{tabular}




\begin{tabular}{|l|l|l|}
\hline $\begin{array}{l}\text { Victor Hensen (1835- } \\
1924)\end{array}$ & $\begin{array}{l}\text { Studien Über Das Gehörorgan Der } \\
\text { Decapode }\end{array}$ & 1863 \\
\hline $\begin{array}{l}\text { Walter Faxon (1848- } \\
1920)\end{array}$ & $\begin{array}{l}\text { Bulletin of the Museum of Comparative } \\
\text { Zoology, Cambridge Mass. v. I e v. V }\end{array}$ & 1879 \\
\hline $\begin{array}{l}\text { William F. Kirby } \\
(1844-1912)\end{array}$ & $\begin{array}{l}\text { A synonymic catalogue of diurnal } \\
\text { Lepidoptera }\end{array}$ & 1871 \\
\hline $\begin{array}{l}\text { William Forsel Kirby } \\
(1844-1912)\end{array}$ & $\begin{array}{l}\text { Synonymic Catalogue of Diurnal } \\
\text { Lepidopter }\end{array}$ & 1871 \\
\hline
\end{tabular}

Quadro 1: Livros consultados e referenciados por Müller em suas publicações nos Archivos do Museu Nacional

É interessante ressaltar que a utilização de fontes diversificadas para oferecer credibilidade às pesquisas também é um método similar encontrado no inglês Charles Darwin, conforme pesquisa de Regner (2006, p.351-378) que apontou na investigação da Origem dos pombos domésticos de Origin, a utilização por Darwin de fontes diversas para oferecer credibilidade científica, como criadores, enciclopédia chinesa, bíblia, escritos de autores romanos clássicos, etc. Outro ponto de similaridade entre ambos é a introdução no discurso científico de conceitos como acaso, singularidade, probabilidade, característicos da ciência moderna; em uma época em que a filosofia era dominada por metodologias baseadas no determinismo das leis físicas. Convém ressaltar também que o período em que Darwin trabalhou na publicação de Origin, foi o mesmo período em que surgia a filosofia da ciência na Inglaterra. Seu método, porém, já não se adaptava às prescrições clássicas da filosofia da ciência, visto que levantava questões, fazia observações, estabelecia hipóteses fazendo com que através de suas especulações científicas, se aproxime dos cientistas modernos.

\section{Amizade e discussões científicas entre Müller e Darwin}

$\mathrm{Na}$ historiografia tradicional, Müller geralmente é conhecido como o brasileiro que se correspondeu com Darwin (SAWAYA, 1996, p.51-68; FRIESEN, 1997, p.89-124; ZILLIG, 1997, p.11; WEST, 2003, p.9-17). Em nossas pesquisas, subsidiadas por artigos, correspondências e documentos, percebemos que Müller, de um simples 'correspondente' e coadjuvante defensor das ideias darwinianas, pode ser compreendido como um pesquisador que, em parceria com Darwin e em diálogo frequente com o estudioso inglês, contribuiu para estabelecer o conjunto das teorias de evolução no século XIX.

A amizade entre os dois naturalistas durou dezessete anos, entre 1865 a 1882, ano da morte de Darwin. Acredita-se que a primeira destas cartas tenha 
sido escrita por Charles Darwin, visto que a primeira das cartas disponíveis na bibliografia é datada de 1865, enviada por Darwin após ter lido o livro de Müller. Se Müller tivesse escrito a Darwin, após o conhecimento e leitura de Origin, que ocorreu em 1861, teríamos mais cartas disponíveis e datadas anteriormente a esta (ZILLIG, 1997, p.13).

Zillig (1997) que realizou a tradução das cartas disponíveis entre os dois naturalistas, encontrou em suas pesquisas 39 cartas endereçadas de Darwin a Müller e 34 de Müller a Darwin. Dentre os assuntos discutidos pelos naturalistas, notamos que Darwin encomendava ao amigo residente no Brasil, muitas pesquisas sobre assuntos que não poderia pesquisar na Europa, exemplo dos tucanos, orquídeas e bromélias. A influência dos estudos de Müller sobre Darwin ainda é assunto que carece de mais pesquisas na historiografia; porém, cabe destacar que apenas nas edições posteriores de Origin, corrigidas pelo autor, o nome de Müller é citado mais de 17 vezes (ZILLIG, 1997, p.2), demonstrando a influência que as ideias de Müller tinham sobre as pesquisas do naturalista inglês.

Analisando as publicações de Müller no Museu Nacional, percebemos grande influência, do conjunto das teorias estabelecidas por Darwin, principalmente em relação ao conceito de seleção natural apresentado pelo autor em Origin (1859) e também sobre seleção sexual publicado em The descent of man and selection in relation to sex (DARWIN, 1871) para a diversidade das espécies.

É importante ressaltarmos que Darwin aceitava a seleção natural como o principal mecanismo de transformação das espécies; porém não descartava a ação de outros mecanismos, como por exemplo, a herança dos caracteres adquiridos pela lei do uso e do desuso; pensamento também seguido por Müller para explicar a ausência ou presença de certas estruturas aparentemente sem função em diferentes organismos.

West (2009, p.45-58) demonstra alguns dos conceitos estabelecidos por Darwin presentes nos trabalhos de Müller. A descendência comum, por exemplo, teoria pela qual todo grupo de organismos descendem de um ancestral comum (DARWIN, 1859, p.458), foi utilizada por Müller em seu livro Für Darwin para explicar as diferentes adaptações encontradas nos tipos de respiração dentro dos caranguejos. West $(2009$, p.50) também exemplifica a apropriação de Müller do conceito de multiplicação das espécies, evoluindo de variações ou de outras preexistentes, para descrever variações em borboletas e em plantas; bem como o conceito de seleção natural, utilizado para a proposição do mimetismo mülleriano e para explicar a metamorfose abreviada de certos crustáceos.

Apesar de concordamos com estes autores, acerca da influência dos trabalhos de Darwin sobre Müller, observamos em nossas pesquisas que Müller também dialogava com Darwin e suas pesquisas influenciavam de forma 
concomitante o estudioso inglês, que se apropriou de muitas das pesquisas desenvolvidas por Müller, para estabelecer conceitos importantes no que ficou conhecido como as Teorias da Evolução no século XIX. Tal influência recíproca, apesar de não ser explorada na historiografia, é demonstrada através das correspondências em que Darwin elogia e encomenda pesquisas a Müller, além de debater com o amigo assuntos científicos sobre os quais tinha dúvidas e que procurava ouvir os comentários de Müller, conforme podemos analisar a partir de alguns excertos de correspondências endereçados a Müller por Darwin, disponibilizados no quadro 2:

\begin{tabular}{|l|l|}
\hline Carta de 10 de agosto de 1865 & Carta de 23 de agosto de 1866 \\
Se o senhor tiver alguma & Sua carta com elegantes desenhos e \\
oportunidade, sendo um habilidoso & flores secas é um bonito objeto. O \\
dissecador, eu gostaria muito que o & caso da Bourlingtonia é inteiramente \\
senhor desse uma olhada no orifício & novo. Quanto ao curso dos vasos nos \\
da base do primeiro par de cirros & vários órgãos da flor ouso dizer que \\
nos cirrípedes. & sua interpretação pode estar certa, \\
(ZILLIG, 1997, p.115) & $\begin{array}{l}\text { e tenho uma pequena dúvida que a } \\
\text { minha estava errada... } \\
\text { (ZILLIG, 1997, p.133) }\end{array}$ \\
\hline
\end{tabular}




\begin{tabular}{|c|c|}
\hline $\begin{array}{l}\text { Carta de } 31 \text { de julho de } 1867 \\
\text { Suas cartas sempre me surpreendem } \\
\text { pelo número de pontos para os } \\
\text { quais o senhor atenta. Desejo que } \\
\text { possa tornar minhas cartas de } \\
\text { algum interesse para o senhor, pois } \\
\text { dificilmente vi um naturalista viver } \\
\text { uma vida tão retirada como o senhor } \\
\text { vive no Brasil. (...) Não esqueça de } \\
\text { me ajudar, se em suas possibilidades, } \\
\text { com respostas a quaisquer de minhas } \\
\text { perguntas sobre expressões, pois o } \\
\text { tema me interessa sobremaneira. } \\
\text { (ZILLIG, 1997, p.164) }\end{array}$ & $\begin{array}{l}\text { Carta de } 03 \text { de junho de } 1868 \\
\text { Estou encantado que o senhor tenha } \\
\text { aprovado o meu livro, pois valorizo } \\
\text { a sua opinião mais do que qualquer } \\
\text { pessoa (...). Muitos agradecimentos } \\
\text { por todos os curiosos fatos acerca } \\
\text { do número desigual de sexos } \\
\text { nos crustáceos; mas quanto } \\
\text { mais investigo este tema, mais } \\
\text { profundamente caio em dúvidas e } \\
\text { dificuldades (....). Por favor, diga- } \\
\text { me onde poderei encontrar algum } \\
\text { relato dos órgãos auditivos nas } \\
\text { Orthoptera. } \\
\text { (ZILLIG, 1997, p.170) }\end{array}$ \\
\hline $\begin{array}{l}\text { Carta de } 22 \text { de fevereiro de } 1869 . \\
\text { Embora o senhor tenha me ajudado } \\
\text { de maneira importante e extensa em } \\
\text { tantas maneiras, estou para pedir } \\
\text { alguma informação em dois outros } \\
\text { tópicos. } \\
\text { (ZILLIG, 1997, p.179) }\end{array}$ & $\begin{array}{l}\text { Carta de } 05 \text { de maio de } 1873 \\
\text { Há cerca de meio ano atrás, o editor } \\
\text { da Nature sugeriu que seria uma } \\
\text { grande empreitada, se um número } \\
\text { de naturalistas estivessem dispostos } \\
\text { a fazer o que o senhor efetivamente } \\
\text { já fez em tão grande escala com } \\
\text { respeito a visita dos insetos. } \\
\text { (ZILJ }\end{array}$ \\
\hline
\end{tabular}

Quadro 2: Excertos escritos por Darwin, endereçados a Müller. Dados coletados de Zillig, 1997.

\section{Considerações finais}

Müller foi um pesquisador original que não se submeteu ao academicismo e preferiu viver em uma terra longínqua, pesquisando e estabelecendo fatos que outros não puderam observar tal qual ele pôde fazer, devido à sua vivência. Ao contrário de Darwin, que muitas vezes não realizava os próprios experimentos que discutia, mas se valia de dados enviados por outros pesquisadores, Müller era um observador minucioso que realizava seus próprios experimentos e buscava escrever sobre todas as estruturas nos maiores detalhes possíveis e conforme seus recursos à época possibilitava. 
Nesse sentido, suas pesquisas foram originais para o contexto científico de sua época e possuem desdobramentos até a atualidade: seus recursos técnicos eram mínimos, não possuía bibliotecas ao seu alcance e nem mesmo outros pesquisadores com quem pudesse debater seus temas ou realizar excursões. Müller não era ligado a nenhuma Universidade, não fazia parte das reuniões científicas na Europa, porém, seu nome era sempre citado nestas reuniões, bem como seus artigos sempre veicularam por importantes revistas da época. A menção de suas pesquisas na Europa deve-se principalmente à troca de correspondências que mantinha com diversos pesquisadores, a maioria deles ligados às Universidades existentes na Alemanha, Itália e Inglaterra. Apesar de toda a sua contribuição, Müller e as formulações feitas a partir de seus trabalhos de pesquisa, são considerados secundários pela historiografia tradicional e pouco incorporados nos livros didáticos, o que nos leva a apontar que a antiga hierarquização entre cientistas 'de gabinete' das metrópoles ao Norte do globo e os pesquisadores sediados no hemisfério Sul, vigente há tanto tempo, ainda se perpetuam nas interpretações correntes, sobretudo nos livros didáticos, bastante eurocêntricos e lineares em suas abordagens do conhecimento biológico, com reflexos na história da ciência e da Biologia contemporâneas, que buscam problematizar e modificar essa situação, a exemplo do que tentamos fazer neste trabalho.

\section{Referências}

BRASIL. Decreto n.6.116, de 09 de fevereiro de 1876. Reorganiza

o Museu Nacional. Disponível em: http://www2.camara.leg.br/ legin/fed/decret/1824-1899/decreto-6116-9-fevereiro-1876-549080publicacaooriginal-64413-pe.html. Acesso em: 25 jan. 2015. 09 fev. 1876. CARULA, K. As Conferências Populares da Glória e as discussões do darwinismo na imprensa carioca (1873-1880). 2007. 189f. Dissertação (Mestrado em História) - Universidade Estadual de Campinas, Campinas. 2007.

CASTRO, M. W. O sábio e a floresta. $2^{\mathrm{a}}$ ed. Campina Grande: Editora da Universidade Estadual da Paraíba, 2007.

DARWIN, C. R. On the origin of species by means of natural selection or the preservation of favoured races in the struggle for life. $1^{\mathrm{a}}$ ed. London: John Murray, 1859.

DARWIN, C. R. The descent of man and selection in relation to sex. $1^{\mathrm{a}}$ ed. New York: Appleton ant Company, 1871.

DELPINO, F. Memorie di biologia vegetale. Firenze: Giunti. 1996.

FRIESEN, G. Fritz Müller em sua contemporaneidade. In: ROQUETTEPINTO, E. et alli. Fritz Müller: reflexões bibliográficas. $1^{\circ}$ ed. Blumenau: Cultura em movimento, 2000. p. 89-124.

Fritz. Direção: José Alfredo Abrão. Florianópolis: Guardachuvas. 22 min. 
2009.

GUALTIERI, R. C. Evolucionismo no Brasil: ciência e educação nos Museus. $1^{a}$ ed. São Paulo: Editora Livraria da Física, 2008.

KEULLER, A. T. A. M. Os estudos físicos de antropologia no Museu Nacional do Rio de Janeiro: cientistas, objetos, ideias, e instrumentos (18761939). $1^{a}$ ed. São Paulo: Humanitas, 2012.

KUHN, T. O caminho desde a estrutura: ensaios filosóficos. São Paulo: Editora Unesp, 2006.

KURY, L. Viajantes naturalistas no Brasil oitoscentista: experiência, relato e imagem. História, Ciências, Saúde, Manguinhos, Rio de Janeiro, v. VIII, suplemento, p. 863-880. 2001.

LIVRO a... Livro de Assentamentos no 5, 1869-1875, ofício s/n, p. 179-180 (Arquivo Histórico do Museu Nacional, Rio de Janeiro). 16 set. 1876. LIVRO b... Livro de assentamentos $n^{\circ} 7,1881 / 1885$, ofício s/n, p. 105 (Arquivo histórico do Museu Nacional, Rio de Janeiro). 04 fev. 1884. LIVRO c... Livro de assentamentos $n^{\circ} 9,1891-1895$ ofício ${ }^{\circ} 86$, p. 20 (Arquivo histórico do Museu Nacional, Rio de Janeiro). 18 jul. de 1891. LOPES, M. M. O Brasil descobre a pesquisa científica: os museus e as ciências naturais no século XIX. $2^{\mathrm{a}}$ ed. Brasília-DF: Editora Universidade de Brasília, 2009.

MAYR, E. Isto é biologia. São Paulo: Companhia das Letras, 2008.

MAYR, E. O que é evolução? Rio de Janeiro: Rocco, 2009.

MORIN, E. Ciência com consciência. $15^{\mathrm{a}}$ ed. Rio de Janeiro: Bertrand Brasil, 2013.

MÜLLER, F. A correlação das flores versicolores e dos insetos pronubos. Archivos do Museu Nacional, v.2, n.1, p.19-23, 1877a.

MÜLLER, F. As máculas sexuais dos indivíduos masculinos de Danais erippus e Danais gilippus. Archivos do Museu Nacional, v.2, n.1, p.25-29, $1877 \mathrm{~b}$.

MÜLLER, F. Os orgãos odoriferos da Antirrhaea archaea Hübner. Archivos do Museu Nacional, v.3, n.1, p.1-7, 1878.

MÜLLER, F. Descripção do Elpidium bromeliarum Crustaceo da Familia dos Cytherideos. Archivos do Museu Nacional, v.4, n.1, p.27-34, 1878. MÜLLER, F. Trichodactylus, siri de água doce, sem metamorphose.

Archivos do Museu Nacional, v.4, n.1, p.125-133, 1892.

MÜLLER, F. Para Darwin. $1^{a}$ ed. Florianópolis: Editora da UFSC. 2009. NETTO, L. Demissão de Fritz Müller. Jornal do Commercio, p. 195. 31 jan. 1892.

REGNER, A. C. K. P. Experimentação, observação e imaginação em Charles Darwin. In: GOLDFARB, A. M.; BELTRAN, M. H. R. O saber fazer e seus muitos saberes: experimentos, experiências e experimentações. $1^{a}$ ed. São Paulo: Editora da Física, 2006. p. 351-378. 
ROQUETTE-PINTO E. Glória sem rumor. In: ROQUETTE-PINTO, E. et alli. Fritz Müller: reflexões bibliográficas. $1^{\mathrm{a}}$ ed. Blumenau: Cultura em movimento, 2000. p.13-50.

SAWAYA, P. Fritz Müller e sua obra. In: ROQUETTE-PINTO, E. et alli. Fritz Müller: reflexões bibliográficas. Blumenau: Cultura em movimento, 2000. p.51-68.

SCHLENZ, E.; FONTES, L. R.; HAGEN, S. A produção científica de Fritz Müller. In: FONTES, L. R.; KUPFER, E.; HAGEN, S. Fritz Müller: príncipe dos observadores. $2^{\mathrm{a}}$ ed. São Paulo: Instituto Martius-Staden, 2012. p. 48-61.

WEST, D. Fritz Müller a naturalist in Brazil. $1^{\mathrm{a}}$ ed. Michigan-USA:

Pocahontas Press, Inc. 2003.

WEST, D. Fritz Müller, o biólogo evolucionista pioneiro no Brasil. In.

DOMINGUES, H. M. B. et alli. Darwinismo, meio ambiente, sociedade. $1^{\text {a }}$ ed. Rio de Janeiro: MAST, 2009. p. 45-58.

WIENER, C. Estudos sobre os sambaquis do sul do Brasil. Archivos do Museu Nacional, v.1, n.1, p.1-20, 1876.

ZILLIG, C. Dear Mr. Darwin: a intimidade da correspondência entre Fritz Müller e Charles Darwin. $1^{a}$ ed. São Paulo: Sky Anima comunicação e design, 1997.

ZILLIG, C. Fritz Müller meu irmão. Blumenau: Cultura em movimento, 2004.

\section{Notas}

1 Optou-se neste trabalho em utilizar a grafia original.

2 Muitos autores atribuem o possível restabelecimento do cargo de Müller por intermédio pessoal de D. Pedro II, informação que não conseguiu ser confirmada, visto que as fontes consultadas possibilitam margem para diversas interpretações.

Artigo recebido em novembro de 2016. Aceito em janeiro de 2016. 